\title{
The Effect of Brown Rice on Superoxide Dismutase Level and Non-alcoholic Fatty Liver in an Sprague-Dawley Rat Model of High- fat High-fructose Diet-induced Obesity
}

\author{
Inggita Kusumastuty ${ }^{1 *}$, Dian Handayani ${ }^{1}$, Shafira Hanifa ${ }^{1}$, Melinda Lisan ${ }^{1}$, Etik Sulistyowati ${ }^{2,3}$ \\ ${ }^{1}$ Department of Nutrition, Faculty of Medicine, Universitas Brawijaya, Malang, Indonesia; ${ }^{2}$ Doctoral Programme, Faculty of \\ Medicine, Universitas Brawijaya, Malang, Indonesia; ${ }^{3}$ Department of Nutrition, Polytechnic of Health, Malang, Indonesia
}

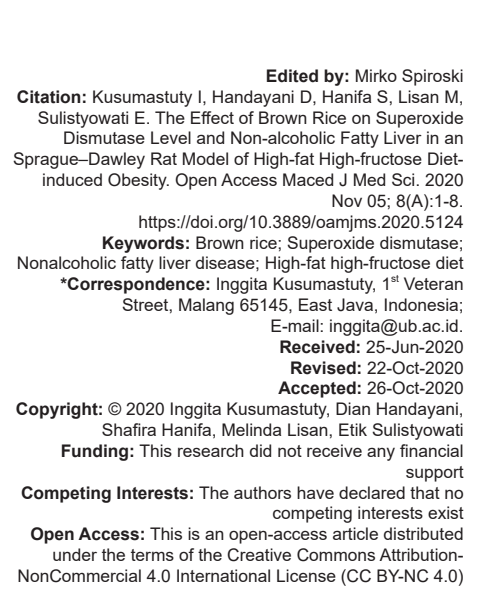

\section{Abstract}

BACKGROUND: Obesity can cause oxidative stress due to the release of free radical components or reactive oxygen species. The accumulation of excess fat in obesity also causes the occurrence of non-alcoholic fatty liver. Brown rice is a functional food with higher fiber, vitamin, mineral, and antioxidant contents than those in white rice.

AIM: This study was aimed to evaluate the effect of brown rice on the superoxide dismutase (SOD) level and nonalcoholic fatty liver in obese Sprague-Dawley rats.

METHODS: An experimental study using a post-test-only control group design was carried out on a SpragueDawley rat model of obesity-induced by a high-fat high fructose (HFHF) diet. Sample selection was done through simple random sampling; rats were divided into five groups, namely the normal diet group (K-), the HFHF diet group $(\mathrm{K}+)$, and HFHF diet groups with the addition of brown rice dose I (P1), dose II (P2), and dose III (P3). The measured variable was the SOD level measured using the spectrophotometric method and the calculation of the percentage of fatty liver cells on the results of a hematoxylin-eosin liver scan of a rat's right lobe.

RESULTS: The dose of brown rice was not affected body weight of the rats significantly compared to the contro groups. Then, there were significant differences in the SOD level and fatty liver in at least two groups $(p=0.01$ and $\mathrm{p}=0.001)$.

CONCLUSION: This study concludes that the administration of brown rice contributes to the increasing SOD leve and decreasing fatty liver in obese model rats.

\section{Introduction}

Obesity is an overweight condition due to the chronic accumulation of energy reserves in the form of fat, and this condition results in an increased risk of metabolic diseases such as type 2 diabetes mellitus and cardiovascular disease. The obesity category established by WHO for Asian populations is a body mass index $\geq 27.5 \mathrm{~kg} / \mathrm{m}^{2}$ [1]. Increased consumption of high-energy foods that are imbalanced with sufficient physical activity (sedentary lifestyle) is a major cause of obesity [2]. A study revealed that consumption of sweetened drinks with a high fructose content can increase the incidence of insulin resistance and central obesity in adults [3], and other studies stated that a group of adults who consume high-fat foods has a risk 9.3 times higher than groups with sufficient fat intake to experiencing central obesity [4].

Obesity can cause oxidative stress due to the release of free radical components or reactive oxygen species (ROS). Several studies report that ROS is the main factor affecting the occurrence of various degenerative diseases such as cancer, diabetes mellitus, and heart disease [5]. The body is able to combat free radicals, but if their amount is excessive, the body is not able to destroy them completely, thus producing an accumulation of oxidative stress. Fat accumulation in obesity conditions makes the adipose tissue a producer of adipokines, which induce the production of ROS.

Furthermore, the obesity condition increases the mechanical burden in the cardiorespiratory function and the body's metabolism that affects the balance of free radicals and antioxidants in the body [6]. It is well known that one role of antioxidants is to counteract free radicals and their bad effects on the body. Superoxide dismutase (SOD) is a type of antioxidant that can protect cells and is found naturally in the human body [7]. However, continuous obesity conditions reduce the levels of SOD so that it can increase the number of free radicals in the body [6]. Thus, antioxidants from the outside are obtained by consuming food sources of antioxidants that can help to combat free radicals in the body.

Administration of high-fat high fructose (HFHF) in experimental animals showed an increase 
in body weight, accumulation of abdominal fat, glucose intolerance, and histopathological damage to the liver, inflammation and hepatocyte damage resulting in nonalcoholic fatty liver disease (NAFLD) [8], [9], [10]. Several studies have been carried out using functional foods to prevent or improve the condition of NAFLD. Research by Doha et al. used functional food in the form of Purslane bread and garden cress bread to reduce weight, improves the condition of dyslipidemia, and reduces lipid peroxidation; these types of bread are effective in preventing the accumulation of fat in the liver [11]. In addition, Dian et al. found that the administration of high-dose shiitake mushroom powder $(6 \%)$ in a high-fat diet for 6 weeks gave a significant difference in low-dose administration (2\%). High-dose mushroom administration has reported to induce increased liver weight, liver steatosis, and higher liver triacylglycerol in the rats. This showed an important reason to explore the benefit of functional food active substances in health [12].

Brown rice is a rice variety that is made without removing the bran layer and the germ during milling. Based on cross-sectional studies, it is known that the number of obese individuals who consume brown rice is higher than that of consumers consuming other variations of brown rice (such as germinated brown rice). Consumption of brown rice that is rich in fiber can reduce in a higher weight loss [13]. Sintanur brown rice is local Indonesian rice, which is richer in fiber and minerals compared to white rice. The total fiber content of Sintanur brown rice is $22.04 \mathrm{~g}$ per $100 \mathrm{~g}$ of rice with $1.79 \mathrm{~g}$ of soluble fiber, $20.25 \mathrm{~g}$ of non-soluble fiber, and $4.9 \beta$ glucan (weight \%) [14].

Research relating benefits of dewaxed brown rice and germinated brown rice to weight loss and fatty liver have been carried out [15], [16], but the benefits of brown rice in improving SOD and the fatty liver condition has not yet been found. This study aims to provide evidence related to the contribution of local Indonesian brown rice (Sintanur variety) to the improvement of the SOD level and the fatty liver condition.

\section{Methods}

\section{Ethical consideration and research design}

This study was conducted on December 2018 - July 2019 and obtained ethical eligibility from the Medical Research Ethics Commission of the Faculty of Medicine, University of Brawijaya, through decree no. 210/EC/KEPK-S3/09/2018. The study design used was an in vivo laboratory experiment on white male Sprague-Dawley strain rats (Rattus norvegicus) in five treatment groups. The study was conducted using the post-test only control group design. This study is on the intervention of the administration of brown rice in the obesity of rats, and the measurement of samples was conducted at the end of the study.

\section{Research sample and treatment group}

The sample of this study was 35 white rats ( $R$. norvegicus) from the Sprague-Dawley strain that were divided into five groups, namely negative control group (K-), positive control $(\mathrm{K}+)$, treatment 1 for dose 1 (P1), treatment 2 for dose 2 (P2), and treatment 3 for dose 3 (P3). The inclusion criteria for the K-group were that the rates had to be aged 5.5-6 months (adult), healthy, and active and the exclusion criteria were obesity with Lee index $>300$, whereas the inclusion criteria for the $\mathrm{K}+, \mathrm{P} 1, \mathrm{P} 2$, and P3 groups were that the rats had to be obese with a Lee index value $>300$ and be healthy and active.

\section{intervention \\ Feed composition and brown rice}

The standard feed composition of AIN-93M is cornstarch, dextrinized cornstarch, sucrose, soybean oil, casein, egg white flour, agar, mineral and vitamin mix AIN, I-cystine, choline bitartrate, and tert-Butylhydroquinone (TBHQ). Contrastingly, the composition of HFHF modified AIN-93M is cornstarch, dextrinized cornstarch, sucrose, fructose, lard, soybean oil, casein, egg white flour, agar, mineral and vitamin mix AIN, l-cystine, choline bitartrate, and TBHQ.

Brown rice (Sintanur variety) intervention given to $\mathrm{P} 1, \mathrm{P} 2$, and $\mathrm{P} 3$ groups was AIN-93M HFHF feeds modified by replacing the weight of cornstarch composition as a source of carbohydrates with brown rice. The amount of brown rice given was $112.5 \mathrm{~g}$ for dose 1 (P1), $225 \mathrm{~g}$ for dose 2 (P2), and $337.5 \mathrm{~g}$ for dose 3 (P3) that represented the average daily rice consumption of Indonesian people based on Statistics Indonesia or BPS (2015) of as much as 370-380 $\mathrm{g}$ [17]. The energy and nutrient values of feed are presented in Table 1.

The drinks given in the $\mathrm{K}+, \mathrm{P} 1, \mathrm{P} 2$, and $\mathrm{P} 3$ groups were $30 \%$ liquid fructose-containing $0.3 \mathrm{kcal} / \mathrm{ml}$ energy and $1.2 \mathrm{~g} / \mathrm{ml}$ carbohydrate.

\section{Diet intake, weight, and lee index}

The diet intake of rats was measured every $24 \mathrm{~h}$, and the bodyweight of the rats was measured once a week during the research. The Lee index was measured at the beginning and end of the study. The Lee's index calculation formula is (BB $(\mathrm{g})^{1 / 3} /$ naso-anal length $[\mathrm{cm}]) \times 10^{3}[18]$.

\section{Blood and liver withdrawal}

Euthanasia of the rats was done using a ketamine injection; then, surgery was performed to 
Table 1: Energy and feed nutrition of each group

\begin{tabular}{llllll}
\hline Ingredient & Group & & & \\
\cline { 2 - 6 } & K- & K+ & P1 & P2 \\
\hline Diet & standard feed AIN-93M & HFHF feed & HFHF feed - Brown rice dose 1 & HFHF feed - Brown rice dose 1 & HFHF feed - Brown rice dose 1 \\
Carbohydrate (\%) & 53.40 & 27.34 & 27.34 & 27.34 & 27.34 \\
Fat (\%) & 21.84 & 52.73 & 52.73 & 52.73 & 19.92 \\
Protein (\%) & 24.76 & 19.92 & 19.92 & 5.12 & 19.92 \\
Energy density (Calorie) & 4.12 & 5.12 & 5.12 & 5.12 & \\
\hline
\end{tabular}

Energy density (Calorie)

draw the blood through the heart and to take the liver. The lobe of the liver used was the right lobe because the accumulation of fat typically only occurs in the right lobe area because of the presence of venous blood vessels that carry factors of scattered lipogenesis in the right lobe. The right lobe of each rat was weighed and stored in a $10 \%$ formalin solution for fixation, blocking, tissue cutting, deparaffinization, and hematoxylin-eosin staining.

\section{SOD level}

Blood that has been taken from the liver was centrifuged at $3000 \mathrm{rpm}$ for $10 \mathrm{~min}$; subsequently, 100 $\mu \mathrm{l}$ serum was taken. The serum was put into a small test tube and added with $100 \mu \mathrm{l}$ xanthine, $100 \mu \mathrm{l}$ xanthine oxidase, $100 \mu$ nitroblue tetrazolium, and $600 \mu \mathrm{l}$ PBS and then homogenized with vortex, after which PBS was added until $2000 \mu \mathrm{l}$. Incubation was carried out at a temperature of $30^{\circ} \mathrm{C}$ for 30 min until serum changed to purple. Readings were carried out with a spectrophotometer at a wavelength of 500-600 nm [7].

\section{Fatty liver}

Tissues that had been through the hematoxylineosin staining process were examined for the amount of fatty liver using a 100x magnification microscope. The Olyvia application is used to obtain tissue photo scans. The calculation was done manually using the cell count application by counting the number of cells that had a fatty liver from 1000 liver cells in the same field of view. The results of the calculation of fatty liver cells were expressed as percentages to assess the fatty liver category. The fatty liver assessment used the categories presented in Table 2.

Table 2: Fatty liver rating categories

\begin{tabular}{ll}
\hline Steatosis & Grade \\
\hline $5-33 \%$ & Mild \\
$34-66 \%$ & Moderate \\
$>66 \%$ & Severe \\
\hline Brunt (1999) in Mark and Xuchen [19]. &
\end{tabular}

\section{Data processing and analysis}

Data were processed using the SPSS software with a significance of 0.05 and a confidence level of $95 \%$. All data were presented as mean \pm SD. An analysis of differences between groups was carried out with the One-Way ANOVA test and the post-hoc Tukey test that fulfilled normality and homogeneity requirements. Data that did not meet the requirements were then tested using the Kruskal-Wallis test and the post-hoc MannWhitney test.

\section{Results}

\section{Energy intake and nutrient substances}

The feeding of HFHF to the $\mathrm{K}+, \mathrm{P} 1, \mathrm{P} 2$, and $\mathrm{P} 3$ groups contributed higher energy and fat compared to that to the K-group, which was at the level of AIN 93M standard feed. The addition of brown rice in groups $\mathrm{P} 1$, P2, and P3 contributed to high fiber intake. The higher the dose of brown rice was, the higher the fiber intake per day was (Table 3).

\section{Body weight and the lee index}

The administration of the HFHF diet contributed to the increase in body weight of rats; this can be seen in the $\mathrm{K}+$ group, which had the highest weight gain, but from the statistical analysis, body weight was not different significantly among groups. By contrast, the mean of changes in the bodyweight of rats has a downward trend to the addition of brown rice in the HFHF feed. For the Lee Index, there were significant differences among groups. The addition of brown rice resulted in a greater decline in the Lee index (Table 4).

\section{SOD level}

The highest mean of the SOD level was in the P3 group, at $28.59 \mathrm{U} / \mathrm{ml}$, and the lowest was in the $\mathrm{K}+$ group at $23.20 \mathrm{U} / \mathrm{ml}$ (Figure 1). The result of the analysis indicated that there were significant differences in at least two groups $(p=0.01$; $p<0.05$; One-way ANOVA). Based on the results of the post-hoc Tukey HSD test, the SOD level in the group of rats on the HFHF diet without brown rice $(\mathrm{K}+)$ decreased but was not significantly different from that of the group given the standard diet $\left(\mathrm{K}^{-}\right)$. SOD levels increased in the groups that were given brown rice (P1, P2, and $P 3)$, but only SOD levels in the $\mathrm{K}+$ group and the $\mathrm{P} 3$ group that had significant differences $(p=0.004 ; p<0.05)$.

\section{Fatty liver}

The average amount of fatty liver in each group is depicted in Figure 2. The highest mean was found in 


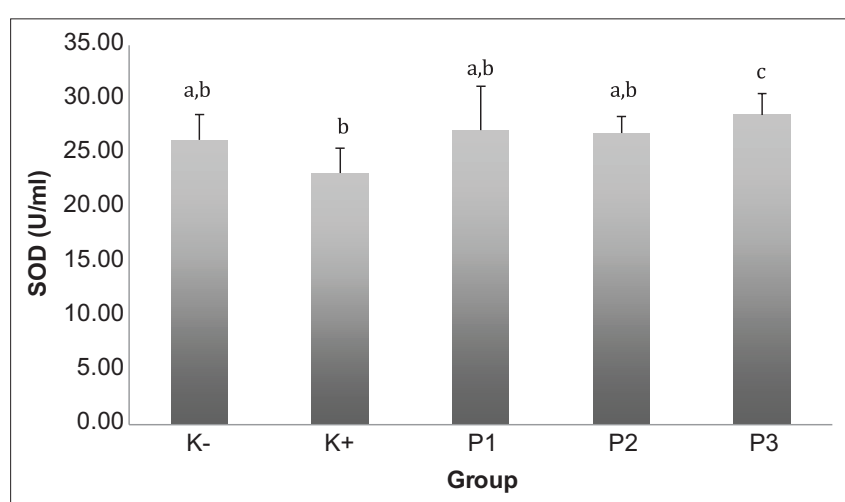

Figure 1: Superoxide dismutase level (U/ml) in each group. The caps represent error standard and the letters above the caps indicate that the amount is different significantly from another group based on Tukey test ( $\alpha$ : $5 \%$ )

the $\mathrm{K}+$ group, at $96.48 \% \pm 1.34 \%$, and the lowest was in the $\mathrm{K}$ group, at $4.98 \% \pm 4.97 \%$. In the groups given brown rice (P1, $P 2$, and $P 3)$, an increase in the dose of brown rice resulted in a decrease in the number of fatty liver.

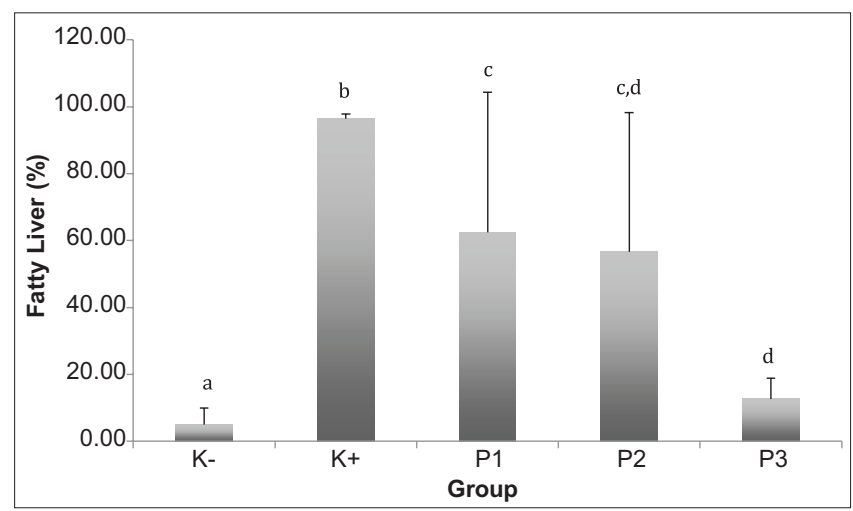

Figure 2: The average amount of fatty liver (\%) in each group. The caps represent error standard and the letters above the caps indicate that the amount is different significantly from another group based on Tukey test ( $\alpha: 5 \%)$

The analysis indicated that there were significant differences in at least two groups $(p=0.001$; $p<0.05$; Kruskal-Wallis). The results of the post-hoc Mann-Whitney test indicated that the $\mathrm{K}$ - group had significant differences in the number of fatty liver with $K+(p=0.004 ; p<0.05), P 1(p=0.011 ; p<0.05), P 2$ $(0.018 ; p<0.05)$, and P3 $(p=0.016)$. This indicates that the administration of HFHF increases the number of fatty liver. The administration of brown rice can reduce the number of indicated liver, as the post-hoc MannWhitney test indicated that the $\mathrm{K}+$ group was significantly different from P1 ( $p=0.016$; $p<0.05)$, P2 ( $p=0.009 ; p<$ $0.05)$, and P3 ( $p=0.006 ; p<0.05)$. The higher the dose of brown rice was, the lower the number of fatty liver was; this was indicated by the post-hoc Mann-Whitney test, in which the P3 group was significantly different from P1 ( $p=0.045 ; p<0.05$ ), although it did not differ significantly from P3 ( $p>0.05)$. The comparison of a cross-sectional scan of the liver between control and treatment groups can be seen in Figure 3.

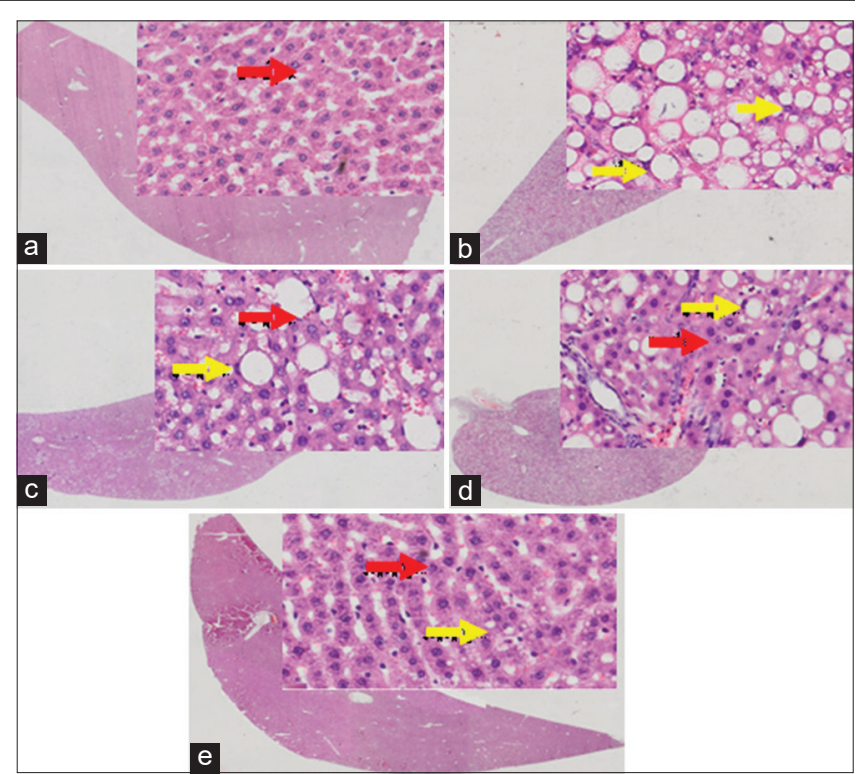

Figure 3: The results of a cross-sectional scan of the liver on a 100x magnifirstinn light microscope from (a) $K-$; (b) $K+$; (c) P1; (d) P2; (e) $P 3 . \longrightarrow$ Red arrow indicates that fatty liver cells are not built up, and there are no lipid droplets in the cytoplasm. Meanwhile, yellow arrow shows that fatty liver cells are built up, and there is a large droplet lipid in the cytoplasm that replaces the small nucleus or "droplet lipids" varying in size in the cytoplasm with the nucleus still in place

\section{Discussion}

The lowest weight gain was in the K-group, and the highest weight gain was in the $\mathrm{K}+$ group. Similarly, an increase in the Lee index occurred in the $\mathrm{K}+$ and $\mathrm{K}$ - groups, but there were decreases in the groups that received brown rice. The higher the dose of brown rice given was, the more the decline of the Lee index was. Changes in body weight and the Lee Index were influenced by food intake and fructose. Fructose is very efficient in inducing lipogenesis so that it can increase the accumulation of abdominal fat even though it does not provide rapid weight gain due to the lower absorption rate of fructose [20]. The increase in the Lee index is in accordance with research conducted by Andressa et al. after 13 weeks of treatment with a highfat diet [21]. By contrast, the fiber content in brown rice affected the feed intake of rats; thus, the feed intake of rats in the groups given the brown rice diet was lower than that in the other groups, which was between 10.09 and 7.94 g/day. Fiber can slow gastric emptying, such that rats experience a decrease in the amount of feed intake [22]; in addition, fiber can suppress food intake by causing an increase in satiety that, in turn, results in a decreased consumption level [23].

SOD levels in the groups that were given the normal diet were higher than those in the $\mathrm{K}+$ group. The composition of energy and nutrients as needed has a positive effect on the body. In this study, giving a normal diet had an effect on weight control compared with giving the HFHF diet. In these conditions, the body is normally 
Table 3: Average energy intake and nutrients per day

\begin{tabular}{|c|c|c|c|c|c|c|}
\hline Group & $\mathrm{K}-$ & $\mathrm{K}+$ & P1 & $\mathrm{P} 2$ & P3 & $\mathrm{p}$-value \\
\hline Energy/day (mean $\pm \mathrm{SD}, \mathrm{Kcal})$ & $55.2 \pm 11.37^{\mathrm{a}}$ & $80.46 \pm 7.75^{b, c}$ & $86.82 \pm 7.01^{\mathrm{b}}$ & $78.07 \pm 5.25^{b, c}$ & $76.21 \pm 5.04^{\circ}$ & 0.002 \\
\hline Carbohydrate/day (mean $\pm \mathrm{SD}, \mathrm{g}$ ) & $7.26 \pm 1.48^{\mathrm{a}}$ & $3.10 \pm 0.32^{b}$ & $2.76 \pm 0.35^{b}$ & $2.28 \pm 0.25^{\circ}$ & $2.17 \pm 0.19^{\circ}$ & 0.000 \\
\hline Fat/day $($ mean $\pm \mathrm{SD}, \mathrm{g})$ & $2.97 \pm 0.61^{a}$ & $5.97 \pm 0.61^{b}$ & $5.32 \pm 0.68^{\mathrm{b}, \mathrm{c}}$ & $4.39 \pm 0.48^{\mathrm{c}, \mathrm{d}}$ & $4.19 \pm 0.37^{d}$ & 0.000 \\
\hline Protein/day (mean $\pm \mathrm{SD}, \mathrm{g}$ ) & $3.37 \pm 0.69^{\mathrm{a}}$ & $2.26 \pm 0.23^{\mathrm{b}}$ & $2.01 \pm 0.25^{\mathrm{b}}$ & $1.66 \pm 0.18^{\mathrm{c}}$ & $1.58 \pm 0.14^{\mathrm{c}}$ & 0.000 \\
\hline Fiber/day (mean \pm SD, g) & $3.86 \pm 0.79^{\mathrm{a}}$ & $2.74 \pm 0.28^{\mathrm{b}}$ & $2.86 \pm 0.28^{b, c}$ & $2.89 \pm 0.32^{\mathrm{b}, \mathrm{c}}$ & $3.17 \pm 0.28^{\mathrm{c}}$ & 0.001 \\
\hline Niacin/day (mean \pm SD, mg) & & & $0.05 \pm 0.007^{(a)}$ & $0.09 \pm 0.01^{(b)}$ & $0.13 \pm 0.01^{(\mathrm{c})}$ & $0.000^{*}$ \\
\hline
\end{tabular}

${ }^{*}$ The value is significantly different according to Kruskal-Wallis test.

Table 4: Mean of changes in rats' body weight and lee index

\begin{tabular}{llllll}
\hline Parameters & $\mathrm{K}-$ & $\mathrm{K}+$ & $\mathrm{P} 1$ & $\mathrm{P} 2$ & $\mathrm{P}$-value \\
\hline Changes in body weight (mean \pm SD, g) & $1.64 \pm 5.46$ & $31.83 \pm 29.65$ & $26.90 \pm 21.26$ & $20.14 \pm 27.64$ \\
Changes in Lee Index (mean \pm SD) & $7.43 \pm 12.03^{(\mathrm{a})}$ & $4.50 \pm 9.57^{(\mathrm{a})}$ & $-10.77 \pm 7.77^{(\mathrm{a}, \mathrm{b})}$ & $-16.61 \pm 8.41^{(\mathrm{b})}$ & $-17.07 \pm 11.42$ \\
\hline${ }^{*}$ The value is significantly different according to one-way ANOVA test. & & 0.292 & $12.39^{(\mathrm{b})}$ & $0.000^{*}$ \\
\hline
\end{tabular}

${ }^{*}$ The value is significantly different according to one-way ANOVA test.

able to fight free radicals in normal amounts. SOD is an antioxidant that can protect cells and is found naturally in the human body. The results of this study indicate that the SOD level increased in the groups that were given brown rice and that there was a significant difference in the SOD levels between the $\mathrm{K}+$ group and the $\mathrm{P} 3$ group. The group that was given the HFHF diet $(\mathrm{K}+)$ had the lowest SOD levels; this is in line with a study conducted by Fikret et al., in which the administration of a high-fat diet to Wistar strain rats for 10 weeks indicated differences in the mean of SOD levels compared to the those in the group given the normal diet as much as $0.23 \mathrm{U} / \mathrm{ml}$ [24]. Another study conducted by Myong et al. indicated that the administration of a high-fat diet to Sprague-Dawley rats experienced differences in the mean of SOD levels; the group given a normal diet had an average SOD level of $124.7 \mathrm{U} / \mathrm{ml}$, and the group given a high-fat diet had a SOD level as high as $71.2 \mathrm{U} / \mathrm{ml}[25]$.

SOD levels in rats fed a high-fat diet can decrease because of the accumulation of fat in the body. Besides, fructose administration in rats causes increased calorie intake and stimulates fat formation in the body [26]. The accumulation of fat can stimulate pro-inflammatory mediators in the form of free fatty acids and some cytokines such as interleukin 6, tumor necrosis factor- $\alpha$, and monocyte chemotactic protein-1, which favor increased ROS. In such conditions, the body uses SOD as a defense against free radicals; thus, the SOD levels decrease [27].

The group of rats given the brown rice diet ( $P 1, P 2$, and $P 3$ ) tended to have higher SOD levels compared to the groups that were given the standard diet and the HFHF diet; this could be due to the presence of phenolic acids as one of the strong antioxidants commonly found in plants [28]. Some forms of phenolic acids can be found in rice, especially in dark rice such as brown rice; phenolic acids, which are most commonly found in brown rice, are trans-ferulic acid and transp-coumaric acid [29]. In brown rice, trans-ferulic acid is found between 161.42 and $374.81 \mu \mathrm{g} / \mathrm{g}$, and transp-coumaric acid is between 35.49 and $81.52 \mu \mathrm{g} / \mathrm{g}$ [30]. These phenolic compounds work as antioxidants directly by finding and capturing several reactive species such as hydroxyl, peroxyl, and superoxide radicals; besides that, phenolic acids also act as chain breakers in the formation of free radicals and prevent lipid peroxidation [29]. These roles of phenolic acids help the body fight free radicals so that the body does not continuously use SOD as a defense [31].

Some other studies that demonstrated increased SOD levels are research conducted by Soo et al., in which white Sprague-Dawley rats given brown rice for 8 weeks with an average rice intake of $4.4 \mathrm{~g} /$ day had higher SOD levels compared to rats given a normal diet with an average difference in SOD levels as much as $2.81 \mathrm{U} / \mathrm{ml}$ [32]. Another study conducted by Jung et al. demonstrated that there were higher differences in the SOD levels as much as $2.15 \mathrm{U} / \mathrm{ml}$ in white Sprague-Dawley rats with an average brown rice intake of $5.2 \mathrm{~g} /$ day compared to rats that only consumed white rice for 6 weeks of treatment [33]. By contrast, research conducted by Chi and Gow on Sprague-Dawley rats injected with $100 \mu \mathrm{g}$ trans-p-coumaric acid had a higher SOD level as much as 6.5-17 $\mathrm{U} / \mathrm{ml}$ compared to the control group after 2 weeks of treatment [34].

The post-hoc Tukey test indicated that the groups that had significantly different SOD levels were between the $\mathrm{K}+$ group and the $\mathrm{P} 3$ group. The P3 group was the highest-dose brown-rice diet group with an average brown rice intake of $2.96 \mathrm{~g} / \mathrm{day}$. The insignificant difference could be because the doses determined still had a short gap or it could also be caused by doses that were not able to increase the SOD levels optimally. Thus, it can be seen that the optimal dose in increasing SOD levels in obese rats is the highest-dose brown rice $(33.7 \%)$ that is suspected through the mechanism of phenolic acid, which works by helping the body in capturing free radicals and blocking lipid peroxidation so that free radicals in the body have decreased, and the SOD level in the body is longer decreasing.

The results of fatty liver in this study indicated that the $\mathrm{K}$ - group did not experience NAFLD conditions, the $\mathrm{K}+, \mathrm{P} 1$, and $\mathrm{P} 2$ groups experienced severe NAFLD conditions, and the P3 group experienced moderate NAFLD. Even though they are in the same category, P1 and P2 groups had lower percentages of the fatty liver than the HFHF group. Fatty liver can occur because of an imbalance of the amount of fat that enters and comes out of the liver [35].

Excessive fructose causes dysregulation in leptin signaling and increased synthesis of Protein 
Kinase b/Forkhead Box Protein $\mathrm{O} 1$ (plays a role in the inactivation of the glycogen synthase-3 enzyme), resulting in an increase in gluconeogenesis and glucose release from the liver that causes hyperglycemia [36]. The fructose derivative compound, fructose-1-phosphate (Fructose-1P), can stimulate enzyme mitogen-activated protein kinase 8 (MAPK8), the connecting enzyme between hepatic metabolism and inflammation. When MAPK8 meets an active protein in the de novo lipogenesis process, namely protein kinase $C$, it will activate insulin receptor substrate 1 so that insulin resistance occurs. Hyperglycemia and insulin resistance causes an increase in the release of free fatty acids from visceral adipose tissue that goes to the liver so that the fat accumulation in the liver increases [10].

A study conducted by the intervention of Vitamin B3 (niacin) addition as much as $0.5-1 \%$ (the percentage is based on average body weight of rats) demonstrated that niacin could significantly prevent the development of hepatic steatosis in mice induced by a high-fat diet NAFLD model. In addition, this study also demonstrated that both groups of rats given niacin had the same steatosis-reducing effect, so it was suspected that niacin administration at lower doses could have a decreased effect of steatosis [37]. Studies in humans provide the same result that providing a dietary intervention through adding niacin according to daily needs (14 g-16 g/day) in individuals with NAFLD conditions can reduce the liver fat level [38].

In $100 \mathrm{~g}$ of brown rice, there is $4.3 \mathrm{mg}$ of niacin. Based on calculations, it is known that the $\mathrm{P} 1$ group consumed approximately $0.02 \%$ niacin; P2, $0.03 \%$; and P3, $0.04 \%$. The percentage of niacin consumption in this study was lower than the percentage of niacin in the study by Shobha et al. [37]. In the study, Shobha et al. proved that the consumption of $0.5 \%$ and $1 \%$ niacin had the same effect in preventing fat accumulation in the liver, whereas, in the results, they found that niacin doses of $0.02 \%$ and $0.04 \%$ had significant differences in the amount fatty liver cells. These results complement the results of the statement in a study conducted by Shobha et al. that niacin interventions at lower doses can have a decreasing effect and significant differences between doses [37].

In addition, in this study, high fiber involvement was also an important factor in decreasing liver fat accumulation. The fiber consumed will experience fermentation and act as a prebiotic in the intestine, so it can increase bacteria that are beneficial to the body, such as Bifidobacteria and Lactobacilli, reduce luminal $\mathrm{pH}$, and inhibit the growth of pathogens. Increasing the number of beneficial bacteria in the body can prevent the development of hepatic steatosis, increase glucose tolerance, decrease serum Lipopolysaccharide, and inhibit the pro-inflammatory response produced from endotoxins. Fiber fermentation produces short-chain fatty acids (SCFA), which acts as a ligand for G-proteincoupled receptor (GPR) in intestinal epithelial cells.
When SCFA activates GPR43, there is an increase in insulin signaling activation, decreased intestinal permeability, prevention of inflammation, and bacterial translocation into the portal vein and liver, whereas GPR41 activation by SCFA can increase energy expenditure. Intestinal microbiota can convert primary bile acids into secondary bile acids, which have selective properties in bacteria in the intestine. In addition, bile acids also play a role in improving choline metabolism by modulating farnesoid $X$ receptor signaling so that it can reduce the synthesis of fatty acids and triglycerides and reduce gluconeogenesis in the liver. A study indicated that in germ-free mice, intestinal microbiota plays a role in increasing the work of key enzymes that play a role in the biosynthesis of de novo fatty acid, including acetylCoA carboxylase and fatty acid synthase; additionally, intestinal microbiota increases LPL activity by inhibiting FIAF, which is an inhibitor of LPL [39].

Based on the results obtained, it can be concluded that brown rice has a positive effect on decreasing fat accumulation in liver cells, and the added dose of brown rice influences the effect of decreasing fat accumulation. This is proven by the highest reduction in fat accumulation in the group of rats that received the highest dose of brown rice (P3). Regarding the role of fiber and niacin in brown rice, it is suspected that niacin has a greater role in reducing the accumulation of fat in the liver. This is supported by several studies conducted to prove that niacin is a substance used for the treatment of dyslipidemia, cardiovascular disease, and reduction of hepatic steatosis [37], [38], [40]. Contrastingly, for fiber, no studies have been found that test the effect of fiber in NAFLD patients [41]. Based on our results, more experimental studies with a large sample size are needed to ensure and document of the comprehensive results.

\section{Conclusion}

Sintanur brown rice has high antioxidant and fiber contents. Administration of Sintanur brown rice to obese rats given the HFHF diet can improve the SOD levels and the incidence of fatty liver.

\section{References}

1. National Institute for Health and Care Excellence. Obesity: Identification, Assessment and Management. Available from: https://www.nice.org.uk/guidance/cg189. [Last accessed on 2020 Jun 14].

2. Minarto M. Pedoman Pencegahan dan Penanggulangan Kegemukan dan Obesitas Pada anak Sekolah. Jakarta Indonesia: Kementerian Kesehatan Republik Indonesia; 2012. 
3. Wei TL, Te FC, Hsiao LH, Chun YL, Sharon T, Pei WW, et al. Fructose-rich beverage intake and central adiposity, uric acid, and pediatric insulin resistance. J Pediatr. 2016;171:90-6.e1. PMid:24475021

4. Fatimah ZB, Saifuddin S, Rahayu I. Consumption pattern towards the incidence of central obesity in employee of government in Bupati Office Jeneponto. Indones J Public Health. 2013;9:1-14.

5. Geoffrey MC. The cell: A Molecular Approach. Washington, DC: ASM Press; 2003.

6. Gisti R, Farida NR, Hery W. Aktivitas superoksida dismutase tikus diabetes yang diberi ekstrak batang kapulaga dan glibenklamid. Scr Biol. 2014;1:1-8. https://doi.org/10.20884/1. sb.2014.1.3.42

7. Regi P, Dasrul D, Sugito S, Muslim A, Zuhrawati Z, Syafruddin S The effect of Vitamin $E$ to superoxide dismutase serum level in diabetes mellitus induced white rat (Rattus norvegicus). J IImiah Mahasiswa Vet. 2018;2:442-9.

8. Zhang Z, Wang Z, Yang Z, Niu Y, Zhang W, Xiaoyong L, et al. A novel mice model of metabolic syndrome: The high-fat-high-fructose diet-fed ICR mice. Exp Anim. 2015;64(4):435-42. https://doi.org/10.1538/expanim.14-0086 PMid:26134356

9. Kanokwan J, Nattharat J, Chariya P. A high-fat, highfructose diet induces antioxidant imbalance and increases the risk and progression of nonalcoholic fatty liver disease in mice. Scientifica (Cairo). 2016;2016:5029414. https://doi.org/10.1155/2016/5029414 PMid:27019761

10. Jung SL, Michele MS, Annie V, Jean MS, Robert HL. The role of fructose in the pathogenesis of NAFLD and the metabolic syndrome. Nat Rev Gastroenterol Hepatol. 2010;7:251-64. PMid:20368739

11. Doha AM, Sherein SA, Hend AE, Rasha SM. Preparation and evaluation of functional foods for prevention of nonalcoholic fatty liver disease. Pak J Biol Sci. 2018;21:454-62. PMid:30724047

12. Dian H, Barbara JM, Jiezhong C, Simon HJ, Todd WM, Xu FH. A high-dose shiitake mushroom increases hepatic accumulation of triacylglycerol in rats fed a high-fat diet: Underlying mechanism. Nutrients. 2014;6:650-62. https://doi.org/10.3390/nu6020650 PMid:24566434

13. Shaw W, Shoichi M, Azusa H. Effects of brown rice on obesity: GENKI study I (cross sectional epidemiological study). J Obes Chronic Dis. 2018;2:12-9. https://doi.org/10.17756/ jocd.2018-013

14. Etik S, Achmad R, Setyawati S, Dian FH. The identification of characteristic macro and micronutrients and the bioactive components of indonesian local brown rice as a functional feed in obesity nutrition therapy. Curr Nutr Food Sci. 2019;15:1-7. https://doi.org/10.2174/1573401315666190328223626

15. Hiroyuki I, Toshiyuki S, Naoki N, Takashi N, Chie K, Maya $U$, et al. Dewaxed brown rice feed improves fatty liver in obese and diabetic model mice. Anticancer Res. 2018;38:4339-45. https://doi.org/10.21873/anticanres.12734 PMid:29970571

16. Jin NH, MiES, Won CL, Seung TL, Hong YC. Anti-obesity effects of germinatedbrownriceextractthroughdown-regulation oflipogenic genes in high fat diet-induced obese mice. Biosci Biotechnol Biochem. 2012;76:1068-74. https://doi.org/10.1271/bbb.110666 PMid:22790925

17. Indonesia Central Bureau of Statistics. Rata-rata Konsumsi per Kapita 2007-2015. Jakarta, Indonesia: Indonesia Central Bureau of Statistics; 2015.

18. Sang IL, Jae WK, Ye KL, Seung HY, In-Ae L, Joo WS, et al. Anti-obesity effect of Monascus pilosus mycelial extract in high fat diet-induced obese rats. J Appl Biol Chem. 2011;54:197-205.

\section{https://doi.org/10.3839/jabc.2011.033}

19. Mark B, Xuchen Z. Non-alcoholic fatty liver disease: An expanded review. World J Hepatol. 2017;9:715-32. PMid:28652891

20. Sijiani P. Consuming excessive amount of fructose may affect our health. J Public Health. 2011;10:173-89.

21. Andressa BM, Paulo AN, Carmen AP, Bruno LA Karen NS, Manuela AC. Obesity induction with high fat sucrose in rats. Arq Bras Cir Dig. 2013;26:17-21. PMid:24463893

22. Verhoeven C, Yekti W. The Effect of Peanut Butter Administration with Red Bran Substitution on Blood Glucose Levels of Diabetic Rats. J Nutr Coll. 2015;4:423-7. https://doi.org/10.14710/jnc. v4i4.10120

23. Michelle JC, Joanne LS. The effect of fiber on satiety and food intake: A systematic review. J Am Coll Nutr. 2013;32:200-11 PMid:23885994

24. Fikret E, Dogan A, Fatma M, Boztepe O, Bekir SP, Sahin S. The effect of diet induced obesity on testicular tissue and serum oxidative stress parameter. Acta Urol Esp. 2011;36:153-9. PMid:21959063

25. Myeong HK, Eun JL, Jeong MC, Ki JN, Taeho O, Kil SK Antioxidant and hepatoprotective effects of fermented red ginseng against high fat diet-induced hyperlipidemia in rats. Lab Anim Res. 2016;32(4):217-23. https://doi.org/10.5625/ lar.2016.32.4.217

26. Maria CFS, Iwan B. Efek fruktosa dan glukosa terhadap kadar trigliserida plasma. J Kes Masy. 2011;11(1):39-47.

27. Rosa V, Lucrezia G, Camilla C, Elisabetta S, Donatella P. Biomarkers of oxidative stress in metabolic syndrome and associated disease. Oxid Med Cell Longev. 2019;2019:8267234.

28. Martha G, Mercedes B, Rosa C, Javier P. Phenolic Acids: Natural Product. Heidelberg: Springer; 2013.

29. Melissa W, Enio, M. Phenolic compounds and antioxidant activity of rice. Braz Arch Biol Technol. 2011;5(2):371-7.

30. Gong ES, Luo SJ, Li T, Liu CM, Zhang GW, Chen J, et al. Phytochemical profiles and antioxidant activity of brown rice varieties. Food Chem. 2017;227:432-43. PMid:28274454

31. Asri W. The role of antioxidants for health. Indo J Biotechnol Med. 2014;3(2):59-68.

32. Chung SI, Ham TH, Kang MY. Effect of germinated pigmented rice "Superjami" on the glucose level, antioxidant defense system, and bone metabolism in menopausal rat model. Nutrients. 2019;11(9):2184. https://doi.org/10.3390/nu11092184 PMid:31514360

33. Jung YK, Min HD, Sang SL. The effects of a mixture of brown and black rice on lipid profiles and antioxidant status in rats. Ann Nutr Metab. 2006;50(4):347-53. PMid:16809902

34. Chi TY, Gow CY. Induction of hepatic antioxidant enzymes by phenolic acids in rats is accompanied by increased levels of multidrug resistance associated protein 3 mRNA expression. J Nutr. 2006;136(1):11-5. https://doi.org/10.1093/jn/136.1.11 PMid:16365051

35. Charlotte JG, Leanne $H$. The influence of dietary fat on liver fat accumulation. Nutrients. 2014;6(11):5018-33. https://doi.org/10.3390/nu6115018 PMid:25389901

36. Dong MZ, Rui QJ, Ling DK. High dietary fructose : Direct or indirect dangerous factors disturbing tissue and organ functions. Nutrients. 2017:9(4):335. https://doi.org/10.3390/nu9040335 PMid:28353649

37. Shobha HG, Gary DK, Nils L, Moti LK, Vajinath SK. Therapeutic Role of niacin in the prevention and regression of hepatic steatosis in rat model of nonalcoholic fatty 
liver disease. Am J Physiol Gastrointest Liver Physiol. 2014;306(4):320-7. https://doi.org/10.1152/ajpgi.00181.2013 PMid:24356885

38. Kataryzna L, Caroline W, Konstantinos K, Jurgen M, Fritz S, Marjo G, et al. Dietary niacin intake predicts the decrease of liver fat content during a lifestyle intervention. Sci Rep. 2019;9(1):1303. PMid:30718741

39. Yun J, Yue Y, Zuru L, Weizhen Z. Gut microbiotaderived components and metabolites in the progression of non-alcoholic fatty liver disease (NAFLD). Nutrients.
2019;11(8):1712

PMid:31349604

https://doi.org/10.3390/nu11081712

40. Miao $\mathrm{H}$, Winnie CW, Shizuya $\mathrm{Y}$, David KW, Lin S, Defeng $W$, et al. Liver fat reduction with niacin is influenced by DGAT-2 polymorphisms in hypertriglyceridemic patients. J Lipid Res. 2012;53(4):802-9. PMid:22315393

41. Carolina MP, Gema F, Javier E. Impact of nutritional changes on nonalcoholic fatty liver disease. Nutrients. 2019;11(3):677. PMid:30901929 